University of Wollongong

Research Online

Australian Institute for Innovative Materials -

Papers

Australian Institute for Innovative Materials

$1-1-2018$

\title{
Metal-Organic Framework-Derived Sea-Cucumber-like FeS2@C Nanorods with Outstanding Pseudocapacitive Na-Ion Storage Properties
}

Zhenxiao Lu

Taiyuan University of Technology

Nana Wang

Taiyuan University of Technology, University of Wollongong, nw415@uowmail.edu.au

Yaohui Zhang

Taiyuan University of Technology

Pan Xue

Taiyuan University of Technology

Meiqing Guo

Taiyuan University of Technology

See next page for additional authors

Follow this and additional works at: https://ro.uow.edu.au/aiimpapers

Part of the Engineering Commons, and the Physical Sciences and Mathematics Commons

Research Online is the open access institutional repository for the University of Wollongong. For further information contact the UOW Library: research-pubs@uow.edu.au 


\title{
Metal-Organic Framework-Derived Sea-Cucumber-like FeS2@C Nanorods with Outstanding Pseudocapacitive Na-lon Storage Properties
}

\author{
Abstract \\ Sodium-ion batteries (SIBS) are supposed to be attractive energy strorage and supply devices due to the \\ abundant reserves of sodium. Their limited specific capacity and rate capacity, however, are standing in \\ the way of the extensive application of SIBs. It is reported herein that porous sea-cucumber-like FeS2@C \\ nanorods can act as efficient cathode materials to satisfy the rigorous requirements of the proposed \\ applications. The fabrication of the sea-cucumber-like FeS2@C nanorods involves the hydrothermal \\ growth of F-MIL (where F = Fe, MIL = materials from the Lavoisier Institute) nanorods, and subsequent \\ sulfidation. The electrochemical results demonstrate that the FeS2@C nanorods are an outstanding \\ cathode material for SIBs with high specific capacity $(385 \mathrm{mAh} / \mathrm{g})$, ultralong lifetime $(160 \mathrm{mAh} / \mathrm{g}$ after 10 \\ 000 cycles at $20 \mathrm{~A} / \mathrm{g}$ ), and exceptional rate capability. The metal-organic framework (MOF) template \\ method provides a useful route toward the development of high-performance electrode materials with \\ robust power and cyclability. \\ Disciplines \\ Engineering | Physical Sciences and Mathematics \\ Publication Details \\ Lu, Z., Wang, N., Zhang, Y., Xue, P., Guo, M., Tang, B., Xu, X., Wang, W., Bai, Z. \& Dou, S. (2018). Metal- \\ Organic Framework-Derived Sea-Cucumber-like FeS2@C Nanorods with Outstanding Pseudocapacitive \\ Na-Ion Storage Properties. ACS Applied Energy Materials, 1 (11), 6234-6241.

\section{Authors} \\ Zhenxiao Lu, Nana Wang, Yaohui Zhang, Pan Xue, Meiqing Guo, Bin Tang, Xun Xu, Wenxian Wang, \\ Zhongchao Bai, and Shi Xue Dou
}


Metal-Organic Framework-Derived Sea Cucumber-Like FeS ${ }_{2} @$ C Nanorods with Outstanding Pseudocapacitive Na-lon Storage Properties

Zhenxiao Lua ${ }^{\mathrm{a}}$, Nana Wang ${ }^{\mathrm{a}, \mathrm{b}}$, Yaohui Zhang ${ }^{\mathrm{a}}$, Pan Xue ${ }^{\mathrm{a}}$, Meiqing Guo ${ }^{\mathrm{c}}$, Bin Tang ${ }^{\mathrm{a}}$, Xun $\mathrm{Xu}^{\mathrm{b}}$, Wenxian Wang ${ }^{\mathrm{a}}$, Zhongchao Bai ${ }^{\mathrm{a}, \mathrm{b}^{*}}$, Shixue $\mathrm{Dou}^{\mathrm{b}^{*}}$

${ }^{a}$ College of Materials Science and Engineering, Taiyuan University of Technology, Taiyuan, 030024, PRC

${ }^{\mathrm{b}}$ Institute for Superconducting and Electronic Materials, Australian Institute for Innovative Materials, University of Wollongong Innovation Campus, North Wollongong New South Wales 2500, Australia

${ }^{\mathrm{c} C o l l e g e}$ of Mechanics, Taiyuan University of Technology, Taiyuan 030024, PRC

"Corresponding author.

E-mail address: "baizhongchao@tyut.edu.cn

“Shi_dou@uow.edu.au 
ABSTRACT: Sodium-ion batteries (SIBs) are supposed to be attractive energy strorage and supply device due to the abundant reserves of sodium. Their limited specific capacity and rate capacity, however, are standing in way of the extensive application of SIBs. It is reported herein that porous sea cucumber-like FeS $\mathrm{F}_{2} \mathrm{C}$ nanorods can act as efficient cathode material to satisfy the rigorous requirements of the proposed applications. The fabrication of the sea cucumber-like $\mathrm{FeS}_{2} @ \mathrm{C}$ nanorods involves the hydrothermal growth of F-MIL (where F $=\mathrm{Fe}, \mathrm{MIL}=$ Materials from the Lavoisier Institute) nanorods, and subsequent sulfidation. The electrochemical results demonstrate that the $\mathrm{FeS}_{2} @ \mathrm{C}$ nanorods are an outstanding cathode material for SIBs with high specific capacity (385 mAh/g), ultralong lifetime (160 mAh/g after 10000 cycles at $20 \mathrm{~A} / \mathrm{g}$ ) and exceptional rate capablity. The metal-organic framework (MOF) template method provides a useful route towards the development of high performance electrode materials with robust power and cyclability.

KEYWORDS: Sodium ion battery, MOFs, FeS ${ }_{2} @ \mathrm{C}$ nanorods, ultralong lifetime, Pseudocapacitance.

\section{- INTRODUCTION}

Extensive utilization of environmentally-friendly renewable energy including wind, wave, solar power, etc. demands efficient and large-scale energy storage devices because of the intermittency and instability of these forms of energy. Rechargeable batteries with long cycling stability and high energy density are considered ideal bridges to integrate renewable energy into grids. ${ }^{1-6}$ The high price caused by extensive consumption and the limited geographic distribution of lithium, however, makes 
current lithium ion batteries (LIBs) not suitable for large-scale energy storage. ${ }^{7}$ Sodium, as an alkali metal like lithium, possesses similar physicochemical properties to lithium and is more cost-effective. ${ }^{8}$ Thus, SIBs are regarded as a promising substitute for LIBs in large-scale energy storage applications. ${ }^{9}$ Suitable electrode materials are the key to achieving ideal SIBs battery performances in such aspects as high power and long cycling life. ${ }^{8}$ On the cathode side, however, the specific capacity is limited (often lower than $200 \mathrm{mAh} / \mathrm{g}$ ), because of the intrinsic drawback of intercalation-type cathodes, which can only take up one sodium ion per transition metal core. ${ }^{9}$ Therefore, conversion-reaction type materials are more attractive because they can accommodate more than one $\mathrm{Na}^{+}$per transition metal core, resulting in higher theoretical capacities. Among all the conversion-reaction type materials, $\mathrm{FeS}_{2}$ is the most attractive because it is very cheap, naturally abundant, and environmentally benign. However, most of the reported $\mathrm{FeS}_{2}$ has showed poor electrochemical performance with large irreversibility and fast capacity decay during cycling because of large volume changes and low electrical conductivity. Therefore, developing optimized structures to facilitate ion/electron transmission and tolerate repeated $\mathrm{Na}^{+}$insertion/extraction is a precondition for realizing the above-mentioned superiority of iron chalcogenides electrode.

Generally speaking, two main strategies are applied to improve the electrochemical performance of $\mathrm{FeS}_{2}$. One is to design nanostructure to shorten ion/electron transport paths. Another is to form smart combination of $\mathrm{FeS}_{2}$ with other electrically conductive materials to increase the electrical conductivity ${ }^{10,11}$. Pint's group reported 
that decreasing the size of $\mathrm{FeS}_{2}$ can boost the reversibility of the conversion reaction process. Their ultrafine $\mathrm{FeS}_{2}(2-9 \mathrm{~nm})$ exhibited improved electrochemical performances due to the short diffusion length. ${ }^{12} \mathrm{Zhu}$ et al. synthesized $\mathrm{FeS}_{2}$ wrapped in a carbon coating to enhance the electrical conductivity and solve the problem of soluble polysulfide dissolution, thus improving the electrochemical performance. ${ }^{13}$ Recently, using ether-based electrolyte greatly improved the performance of $\mathrm{FeS}_{2}$ based materials. ${ }^{14}$ Although great success was achieved, $\mathrm{FeS}_{2}$ electrode still far from practical application. Therefore, to develop a new type of $\mathrm{FeS}_{2}$ electrode with good cycling stability and high rate capability for SIBs is urgent.

Here, porous sea cucumber-like $\mathrm{FeS}_{2} @ \mathrm{C}$ nanorods constructed by growing $\mathrm{FeS}_{2} @ \mathrm{C}$ nanoflakes on $\mathrm{FeS}_{2} @ \mathrm{C}$ nanorods were synthesized through a hydrothermal process for preparing uniform F-MIL nanorods and a subsequent sulfidation process. The featured nanostructure has many advantages as electrode for batteries. Firstly, the porous structure can efficiently shorten the ion insertion distance, provide more active sites and buffer the volume change during the electrochemical reaction. ${ }^{15-23}$ Secondly, the well-connected carbon networks can not only facilitate charge transport and mass transfer, but also help to stabilize the formed solid electrolyte interphase (SEI) layer. $^{24-27}$ Thirdly, the $\mathrm{FeS}_{2} @ \mathrm{C}$ nanoflakes enlarge the contact area between the electrolyte and the electrode, thus improving the electrochemical performance of the composite. Consequently, the porous sea cucumber-like $\mathrm{FeS}_{2} @ \mathrm{C}$ nanorods delivered outstanding sodium storage properties, including high specific capacity (385 mAh/g), long cycling stability $(160 \mathrm{mAh} / \mathrm{g}$ after 10000 cycles at $20 \mathrm{~A} / \mathrm{g})$, and superior rate 
capability. Our work offers a paradigm of a smart SIBs cathode material that greatly promotes the battery performance.

\section{MATERIALS AND METHODS}

Materials and Preparation of FeS $2 @ C$ Nanorods. The F-MIL nanorods were prepared by a simple hydrothermal method. $0.5406 \mathrm{~g} \mathrm{FeCl}_{3} \cdot 6 \mathrm{H}_{2} \mathrm{O}$ and $0.4153 \mathrm{~g} 1,4$ benzene dicarboxylic acid $\left(1,4 \mathrm{H}_{2}\right.$ bdc acid) were dissolved in $27 \mathrm{~mL}$ dimethyl formamide (DMF) through ultrasonic dispersion and stirring. Then, $3 \mathrm{~mL}$ of 0.4 $\mathrm{mol} / \mathrm{L} \mathrm{NaOH}$ solution was dropped into the above mixture. After stirring for several minutes, the final solution was transferred into a Teflon-lined autoclave and heated at $100{ }^{\circ} \mathrm{C}$ for $12 \mathrm{~h}$ in an oven. The pink product was collected after washing with DMF for three times to remove impurities and dried at $60{ }^{\circ} \mathrm{C}$ overnight, to finally yield the F-MIL nanorods. Appropriate amounts of F-MIL and sulfur powder were placed in a combustion boat and annealed at $500{ }^{\circ} \mathrm{C}$ for $2 \mathrm{~h}$ in nitrogen with a heating rate of $2{ }^{\circ} \mathrm{C} / \mathrm{min}$. The black product was collected and washed with formaldehyde to remove the residual sulfur and leave the sea cucumber-like $\mathrm{FeS}_{2} @ \mathrm{C}$ nanorods.

Morphology and Structure Characterization. The components of the product were identified by X-ray diffraction (XRD; Bruker D8 ADVANCE) with $\mathrm{Cu} \mathrm{K} \alpha$ radiation $(\lambda=0.15418 \mathrm{~nm})$, Raman spectroscopy (NEXUS 670 Micro-Raman Spectrometer), thermogravimetric analysis (TGA; Mettler Toledo TGA/SDTA851 thermal analyzer apparatus) conducted in air and X-ray photoelectron spectroscopy (XPS; Thermo Scientific K-Alpha spectrometer using Al Ka as the X-ray source). A JEOL-1011 transmission electron microscope (TEM) and a JSM-7600F JEOL 
scanning electron microscope (SEM) were used to characterize the morphology of the precursor and the final product after sulfidation. High resolution TEM (HRTEM) measurements were conducted on a JEOL-2110 high-resolution transmission electron microscope with an acceleration voltage of $200 \mathrm{kV}$ to gain insight into the subtler aspects of the structure and the crystallinity.

Preparation of Electrodes. The electrodes were fabricated by mixing $\mathrm{FeS}_{2} @ \mathrm{C}$ nanorods, carbon black, and carboxymethyl cellulose (CMC) in weight ratio of 7:2:1 with deionized water as solvent, and the resultant slurry was coated on a copper foil before drying in a vacuum oven at $60{ }^{\circ} \mathrm{C}$ for $6 \mathrm{~h}$. The electrochemical measurements were conducted on CR2032 coin-type cells, which contained the as fabricated electrode (with active material mass loading of $\sim 1 \mathrm{mg} / \mathrm{cm}^{2}$ ), pure $\mathrm{Na}$ foil as counter electrode, Whatman $\mathrm{GF} / \mathrm{F}$ as separator, and $1 \mathrm{M} \mathrm{NaCF} \mathrm{SO}_{3}$ in diethylene glycol/ dimethyl ether (DEG/DME) as electrolyte. Charge-discharge tests were conducted on a LAND multi-channel battery measurement system at different constant current densities within a voltage window of $0.8-3 \mathrm{~V}$ at $25{ }^{\circ} \mathrm{C}$. The Cyclic voltammograms (CVs) of the batteries were collected on a CHI-760 electrochemical workstation at scan rates ranging from $0.1 \mathrm{mV} / \mathrm{s}$ to $10 \mathrm{mV} / \mathrm{s}$.

\section{- RESULTS AND DISCUSSION}

Phase and Morphology Characterization. The detailed synthesis process for $\mathrm{FeS}_{2} @ \mathrm{C}$ nanorods is schematically illustrated in Scheme1. Firstly, the iron is incorporated in organic molecules during the hydrothermal process to form F-MIL nanorods, which delivers a stable porous structure and high surface area. ${ }^{28-31}$ 
Afterwards, the needle-shaped F-MIL nanorods were calcined under nitrogen atmosphere in the presence of sulfur to obtain the sea cucumber-like $\mathrm{FeS}_{2} @ \mathrm{C}$ nanorods. During the calcination, the organic complex (bdc) in F-MIL was carbonized to form a carbon shell at $500{ }^{\circ} \mathrm{C}$, while the $\mathrm{Fe}^{3+}$ was reduced and combined with $\mathrm{S}$ via the $\mathrm{Fe}-\mathrm{S}$ bonds to form $\mathrm{FeS}_{2}$ nanoparticles dispersed in the carbon shell. Additionally, $\mathrm{FeS}_{2} @ \mathrm{C}$ nanoflakes formed on the surface of the $\mathrm{FeS}_{2} @ \mathrm{C}$ nanorods. As revealed in Scheme 1(b), the-obtained $\mathrm{FeS}_{2} @ \mathrm{C}$ nanorods featured with loose $\mathrm{FeS}_{2}$ nanoparticles encapsulated in carbon shells and $\mathrm{FeS}_{2} @ \mathrm{C}$ nanoflakes dispersed on the surfaces of the nanorods, resulting in the sea cucumber-like structure. Such a special structure imparts several advantages when used as electrode for batteries: firstly, the nano-sized $\mathrm{FeS}_{2}$ particles inside the carbon shell efficiently accelerate the transportation of $\mathrm{Na}^{+}$ and electron; secondly, the interspace between the $\mathrm{FeS}_{2}$ particles could buffer the volume expansion caused by sodiation and facilitate electrolyte permeation; ${ }^{32}$ thirdly, the carbon shell improves the electrical conductivity of the electrode and is beneficial for growth of the SEI film on the outer surface, guaranteeing sufficient internal space for $\mathrm{FeS}_{2}$ particle expansion. ${ }^{27,33-35}$ Therefore, the $\mathrm{FeS}_{2} @ \mathrm{C}$ nanorods deliver a comparable specific capacity, superior rate capacity and outstanding cycling stability as electrode for SIBs.

Scheme 1. Schematic illustration of the (a) synthesis procedure and (b) advantages when used as electrode for $\mathrm{FeS}_{2} @ \mathrm{C}$ nanorods. 


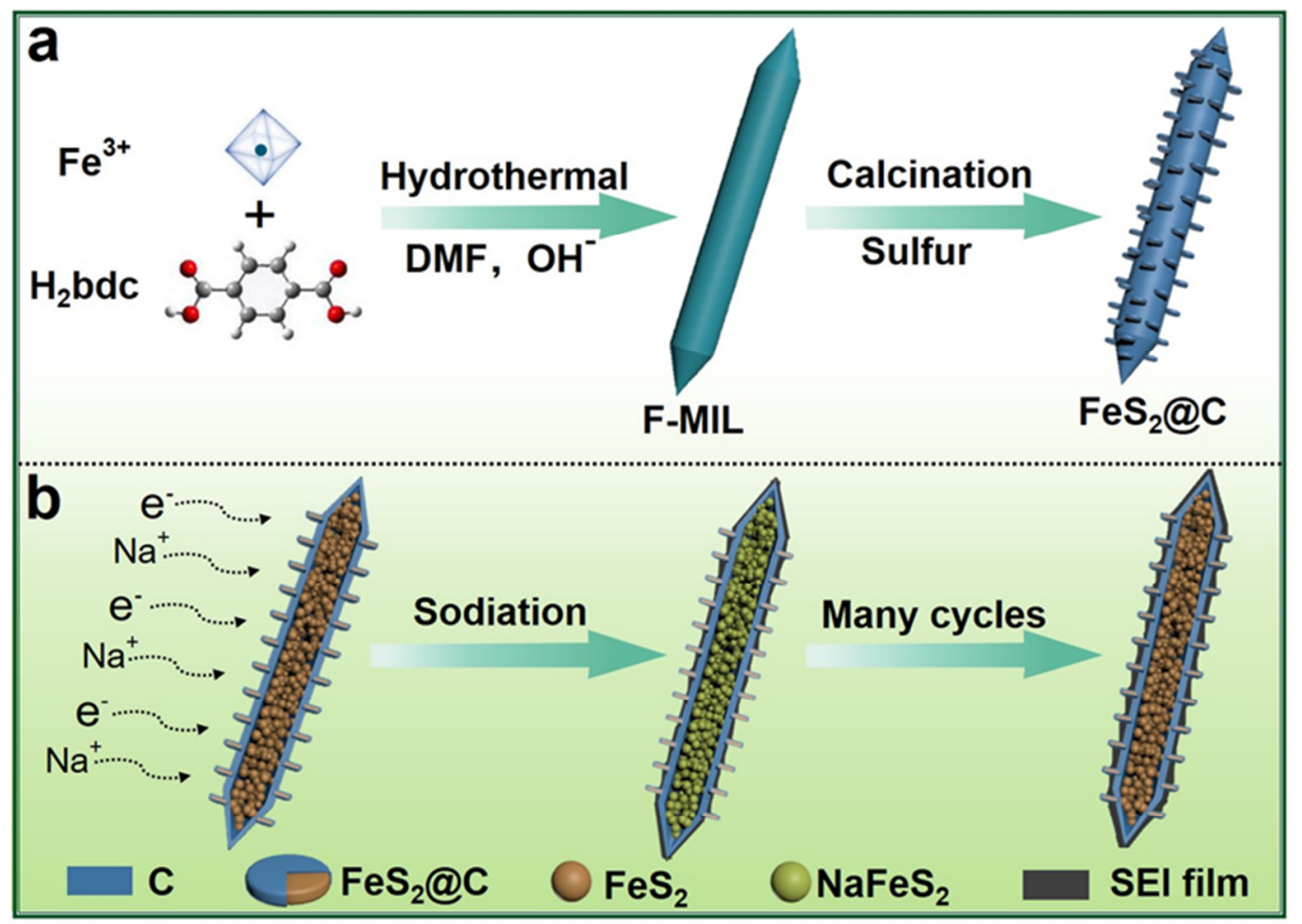

In order to reveal the components and crystallographic structure of the product after sulfidation, XRD testing was conducted as exhibited in Fig. 1a. The distinct strong peaks demonstrate the high crystallinity of the as-prepared $\mathrm{FeS}_{2} @ \mathrm{C}$ nanorods, which can be indexed to $\mathrm{FeS}_{2}$ (JCPDF No. 65-3321) and FeS 2 (JCPDF No. 65-2567). Peaks for the carbon layer are not detected in the XRD pattern because of the amorphous structure of the carbon. However, the peaks located at 1314 and $1544 \mathrm{~cm}^{-1}$ in the Raman spectrum (Fig. 1b) are characteristic of carbon and indicate the presence of the carbon layer. ${ }^{36}$ The small peaks at 336 and $382 \mathrm{~cm}^{-1}$ are derived from $\mathrm{FeS}_{2}{ }^{37}$ The content of $\mathrm{FeS}_{2}$ in the $\mathrm{FeS}_{2} @ \mathrm{C}$ nanorods can be determined by means of thermogravimetric analysis (TGA) (Fig. S1 in the Supporting Information). According to the XRD pattern of the annealed $\mathrm{FeS}_{2} @ \mathrm{C}$ nanorods (Fig. S2 and S3), the weight loss from $200{ }^{\circ} \mathrm{C} \sim 450{ }^{\circ} \mathrm{C}$ is attributable to the comprehensive effect of the transformation of $\mathrm{FeS}_{2}$ to $\mathrm{Fe}_{2}\left(\mathrm{SO}_{4}\right)_{3}$ and the partial oxidation of $\mathrm{C}$. The subsequent 
weight loss at $550{ }^{\circ} \mathrm{C} \sim 600{ }^{\circ} \mathrm{C}$ was due to the thorough decomposition of $\mathrm{Fe}_{2}\left(\mathrm{SO}_{4}\right)_{3}$ into $\mathrm{Fe}_{2} \mathrm{O}_{3}$ and the oxidation of $\mathrm{C}$ to carbon oxides. Thus, the content of $\mathrm{FeS}_{2}$ in the as formed $\mathrm{FeS}_{2} @ \mathrm{C}$ nanorods is $79.9 \%$ based on the law of conservation of mass. ${ }^{38}$ The specific surface area and pore-size distribution of the porous $\mathrm{FeS}_{2} @ \mathrm{C}$ nanorods were revealed by BET method. The type $\square \mathrm{N}_{2}$ sorption isotherms displayed in Fig. S4 indicate that the $\mathrm{FeS}_{2} @ \mathrm{C}$ nanorods possess a specific surface area of $103.7 \mathrm{~m}^{2} / \mathrm{g}$. And the inserted pore-size distribution curve, which based on the BJH method, confirmed that the pore diameter of the $\mathrm{FeS}_{2} @ \mathrm{C}$ is $\approx 12 \mathrm{~nm}$.
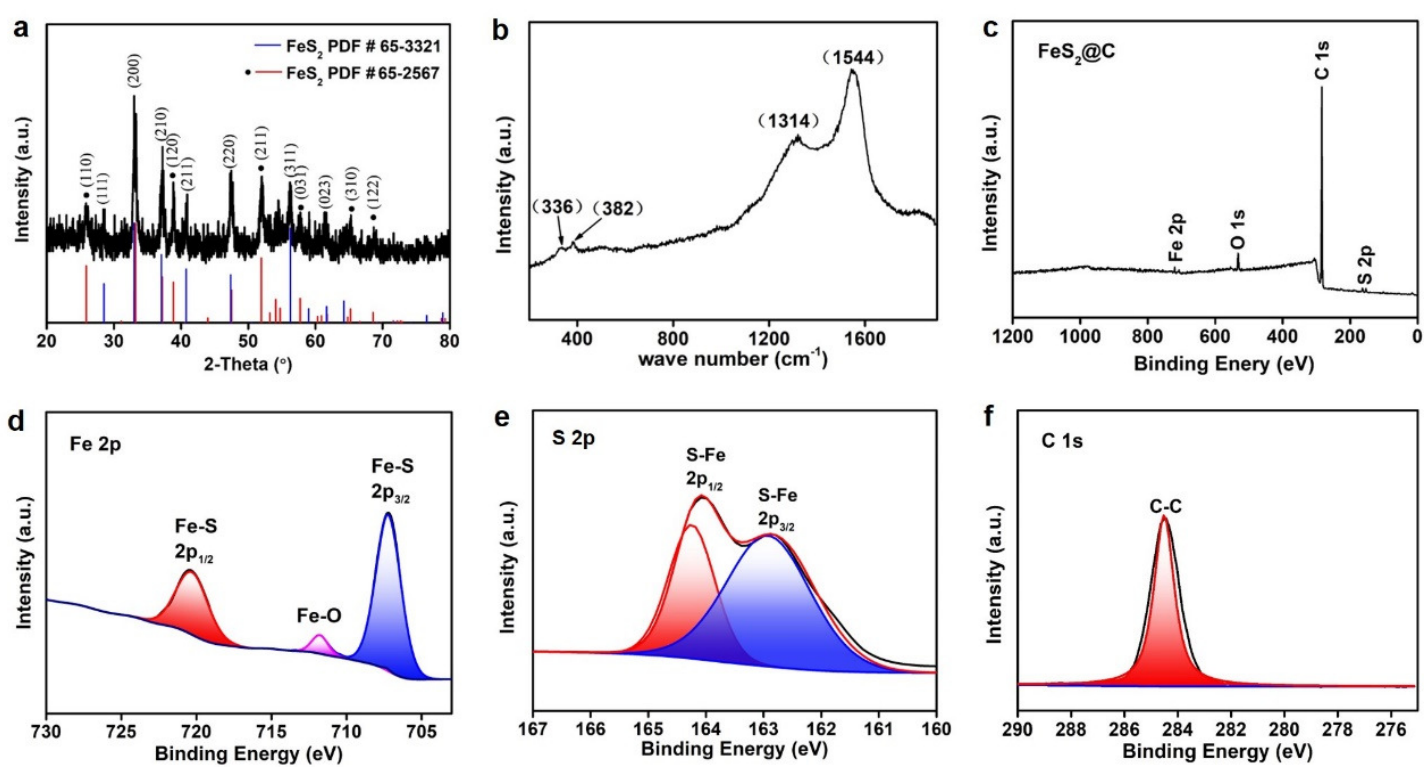

Fig. 1. (a) XRD pattern and (b) Raman spectrum of the of $F e S_{2} @ C$ nanorods. XPS spectra of the $\mathrm{FeS}_{2} @ \mathrm{C}$ nanorods: (c) survey (d)Fe 2p, (e) S 2p, and (f) C $1 \mathrm{~s}$. The components and chemical state of the sample were further characterized via XPS analysis. Fig. 1c shows the survey XPS spectrum of the $\mathrm{FeS}_{2} @ \mathrm{C}$ nanorods, which matches well with the XRD pattern except for slight oxygen pollution due to oxidation of $\mathrm{FeS}_{2} @ \mathrm{C}$ in the air. The two peaks of Fe 2p (Fig. 1d) located at $720.63 \mathrm{eV}$ and $707.33 \mathrm{eV}$ correspond to $\mathrm{Fe} 2 \mathrm{p}_{1 / 2}$ and $\mathrm{Fe} 2 \mathrm{p}_{3 / 2}$ orbitals, indicating the existence of $\mathrm{Fe}^{2+}$. And a small peak located at $711.19 \mathrm{eV}$ was observed, which is due to the $\mathrm{Fe}-\mathrm{O}$ 
contation at the surface of $\mathrm{FeS}_{2} @ \mathrm{C}$ and the oxygen-containing functional groups. ${ }^{39,40}$ The XPS specturn of S 2p (Fig. 1e) exhibits two peaks located at $163.83 \mathrm{eV}$ and $162.45 \mathrm{eV}$, representing $\mathrm{S} 2 \mathrm{p}_{1 / 2}$ and $\mathrm{S} 2 \mathrm{p}_{3 / 2}$, respectively, which is in agreement with the sulfur binding energy of $\mathrm{FeS}_{2}{ }^{39} \mathrm{Fig}$. 1f shows the XPS spectrum of carbon, in which the peak $(284.6 \mathrm{eV})$ is consistent with the binding energy of carbon. These results further confirm the composition of $\mathrm{FeS}_{2} @ \mathrm{C}$ nanorods.
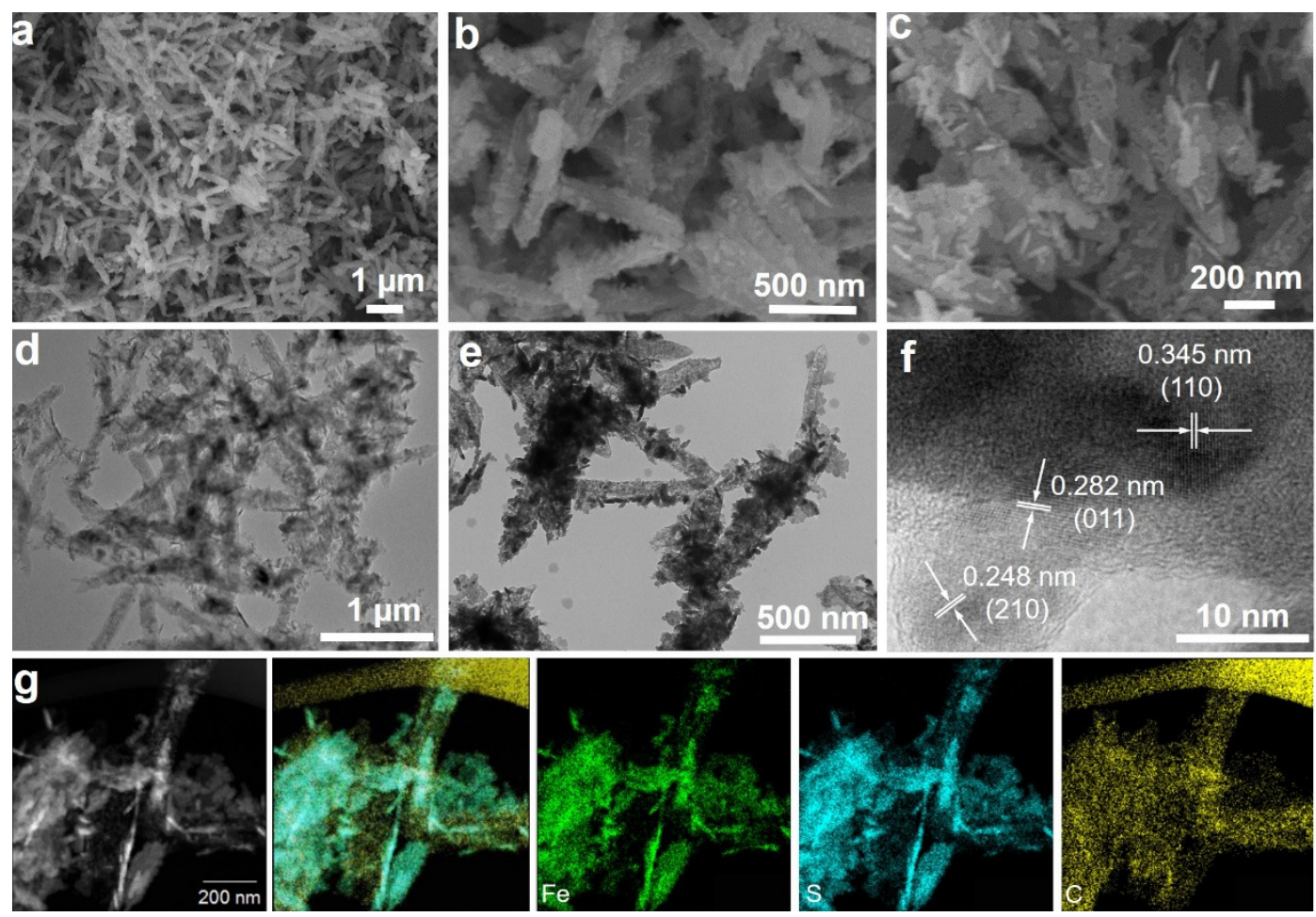

Fig. 2. (a, b and c) SEM images, (d, e and f) HRTEM images and (g) element mapping of $\mathrm{FeS}_{2} @ \mathrm{C}$ nanorods.

The morphology features of F-MIL nanorods and FeS ${ }_{2} @ \mathrm{C}$ were characterized by SEM and TEM at different magnifications. The precursor shows a uniform needle-like one-dimensional structure with length of about $1 \mu \mathrm{m}$ and diameter of 100 nm (Fig. S5). After the sulfurization, the sample basically maintains the original one-dimensional structure and the particle size (length of $1 \mu \mathrm{m}$ and diameter of 100 nm) (Fig. 2a and b), although the surface of sample becomes very coarse (Fig. 2b). Close observation reveals that some nanoflakes have grown on the surface of the 
sample, forming a sea cucumber-like structure. The microstructure of the final product was further investigated via TEM and HRTEM. Interestingly, it should be noted that the solid F-MIL nanorods are converted into porous nanorods encapsulating scattered $\mathrm{FeS}_{2}$ particles (Fig. 2d and e) with space between them (Fig. S6a-c). In addition, abundant plenty of nanoflakes dispersed over the surface of the nanorods, which were demonstrated to be $\mathrm{FeS}_{2}$ covered by a thin carbon layer $(\sim 1.31$ nm) by HRTEM images and element mapping (Fig. S6d, Fig. S7). The formation of the porous structure is due to the Kirkendall effect as previously reported. ${ }^{15}$ Such a porous structure could facilitate permeation of the electrolyte into the inner spaces of the nanorod and contribute to sufficient contact surface between the electrolyte and the electrode material. ${ }^{17}$ Fig. $2 \mathrm{f}$ is a HRTEM image of the crystalline core with clear lattice fringes and amorphous edges, which reflect the carbon shell outside the $\mathrm{FeS}_{2} @ \mathrm{C}$ nanorods. The interplanar spacings of $0.345 \mathrm{~nm}$ and $0.282 \mathrm{~nm}$ were indexed to (110) and (011) planes of $\mathrm{FeS}_{2}$ (JCPDS No. 65-2567), respectively. The $0.248 \mathrm{~nm}$ interplanar spacing can be assigned to (210) planes of $\mathrm{FeS}_{2}$ (JCPDS No. 65-3321). The element mapping displayed in Fig. $2 \mathrm{~g}$ reveals that $\mathrm{Fe}$ and $\mathrm{S}$ are distributed under the $\mathrm{C}$ coating layer, which is consistent with the HRTEM images. 

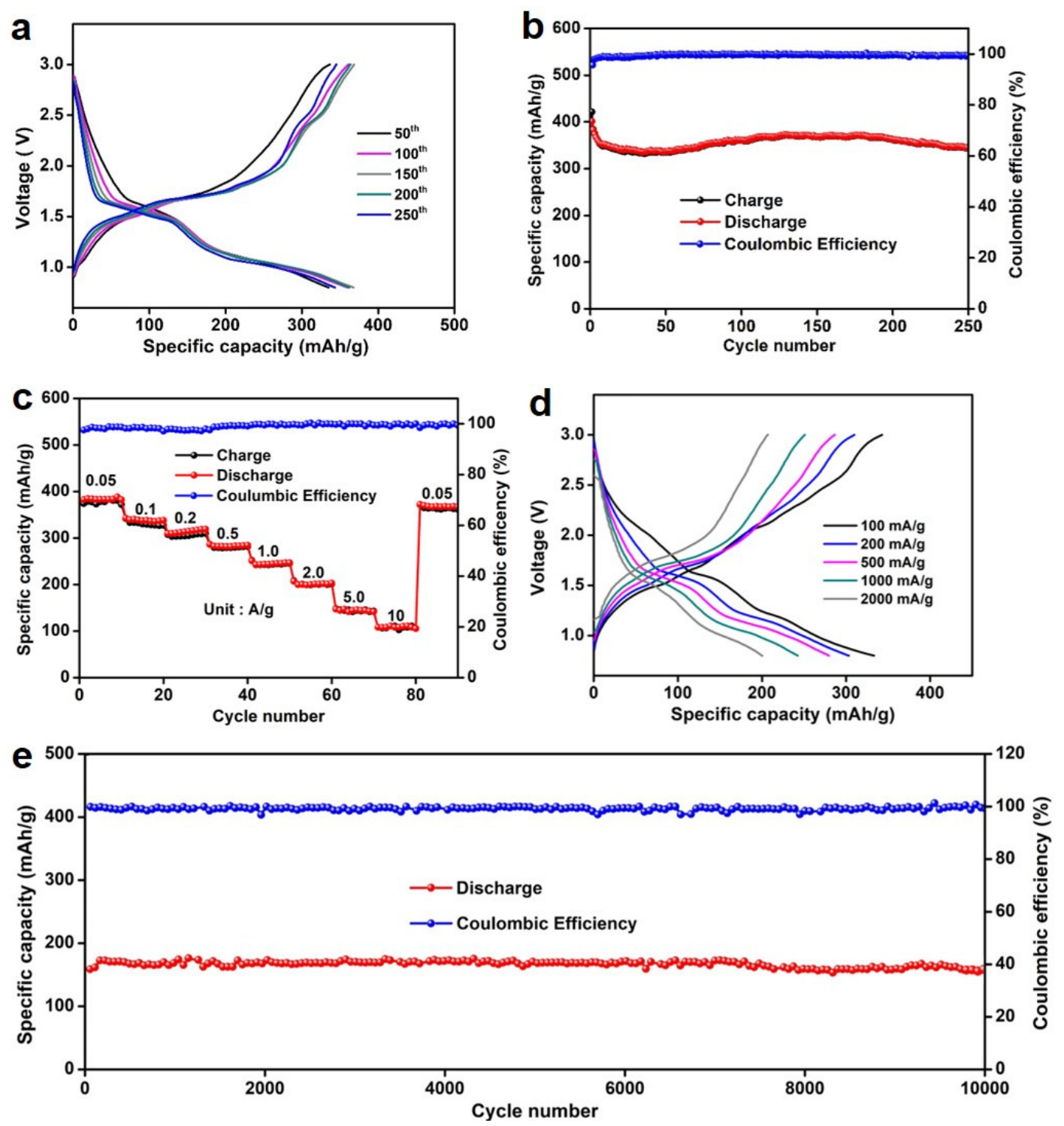

Fig. 3. (a) Charge and discharge curves of $\mathrm{FeS}_{2} @ \mathrm{C} / \mathrm{Na}$ battery at $0.5 \mathrm{~A} / \mathrm{g}$. (b)

Specific capacity and charge/discharge efficiency of $\mathrm{FeS}_{2} @ \mathrm{C} / \mathrm{Na}$ battery at $0.5 \mathrm{~A} / \mathrm{g}$.

(c) Rate capacity at current densities varying from 0.05 to $10 \mathrm{Ah} / \mathrm{g}$. (d) Voltage profiles at different rates. (e) Long cycling performance at the high rate of $20 \mathrm{~A} / \mathrm{g}$.

Electrochemical Properties. The electrochemical properties of the sea cucumber-like $\mathrm{FeS}_{2} @ \mathrm{C}$ nanorods in $\mathrm{SIBs}$ were examined via fabricating $\mathrm{FeS}_{2} @ \mathrm{C} / \mathrm{Na}$ batteries. Galvanostatic cycling profiles of the $1^{\text {st }}, 2^{\text {rd }}, 3^{\text {nd }}, 4^{\text {th }}, 50^{\text {th }}, 100^{\text {th }}, 150^{\text {th }}, 200^{\text {th }}$ and $250^{\text {th }}$ cycles for the $\mathrm{FeS}_{2} @ \mathrm{C}$ electrode with a voltage window between 0.8-3 V at 
current density of $0.5 \mathrm{~A} / \mathrm{g}$ are displayed in Fig. 3a and Fig. S8a. The initial discharge profile displays a steep slope from $2.0 \mathrm{~V}$ to $1.2 \mathrm{~V}$ followed by a long platform which may due to the reaction of embedded $\mathrm{Na}^{+}$with $\mathrm{FeS}_{2}\left(\mathrm{FeS}_{2}+\mathrm{Na}^{+}+\mathrm{e}^{-} \rightarrow \mathrm{NaFeS}_{2}\right)$ and a discharge capacity of $422 \mathrm{mAh} / \mathrm{g}$ is finally achieved. ${ }^{41,42}$ As for the subsequent charge profile, a distinct platform at $2.6 \mathrm{~V}$ and two small plateaus at $1.6 \mathrm{~V}$ and $2.2 \mathrm{~V}$ can be detected, which correspond to the multistep $\mathrm{Na}^{+}$deintercalation from $\mathrm{NaFeS}_{2}$ and formation of the $\mathrm{Na}_{x} \mathrm{FeS}_{2}(x \approx 0.2) .{ }^{41}$ These plateaus restore $95 \%$ of the discharge capacity and a gain in capacity of $402 \mathrm{mAh} / \mathrm{g}$. In the subsequent three cycles, the discharge profiles are similar (with a plateau at $2.1 \mathrm{~V}$ ) but they are completely different from the first discharge profile, manifesting that some irreversible change occur in the electrode after the first discharge. ${ }^{43}$ However, the charge/discharge profiles after 50 cycles tend to be stable and are quite different from the first few cycles, demonstrating a gradual electrode activation process, which has been reported before. $^{33}$ Accordingly, the electrochemical reaction accompanying the $\mathrm{Na}^{+}$ intercalation and deintercalation that occur in the $\mathrm{FeS}_{2} / \mathrm{Na}$ batteries become stable after about 50 cycles. The plateaus at $1.5 \mathrm{~V}$ and $0.9 \mathrm{~V}$ on the $50^{\text {th }}$ discharge profile represent the $\mathrm{Na}^{+}$stepwise intercalation and the formation of $\mathrm{Na}_{x} \mathrm{FeS}_{2}(x \approx 1.6)$, while the two plateaus at $1.5 \mathrm{~V}$ and $1.7 \mathrm{~V}$ on the charge profile represent the $\mathrm{Na}^{+}$ deintercalation and the formation of $\mathrm{Na}_{x} \mathrm{FeS}_{2}(x \approx 0.2) .{ }^{40}$ This result is also agreement with our CV test, which will be discussed later. The cyclability of $\mathrm{FeS}_{2} @ \mathrm{C}$ electrode at current density of $500 \mathrm{~mA} / \mathrm{g}$ is shown in Fig. 3b. The capacity degenerate in the first 30 cycles, but there is a following gradual rise, which may correspond to the slow 
activation and phase change of the electrode. ${ }^{33,41}$ Besides, the additional formation of SEI layer after the initial several cycles may also cause capacity increase.

The rate capability of the assembled $\mathrm{FeS}_{2} @ \mathrm{C} / \mathrm{Na}$ batteries was investigated and is shown in Fig. 3c. In every stage of current density, the sample displays very stable cyclability with Coulombic efficiencies above $98 \%$. Average reversible capacities of 384, 340, 310, 287, 243, 200, 147 and $108 \mathrm{mAh} / \mathrm{g}$ were achieved, at current densities of $0.05,0.1,0.2,0.5,1.0,2.0,5.0$, and $10 \mathrm{~A} / \mathrm{g}$, respectively (Fig. 3c). Additionally, when the current was changed from $10 \mathrm{~A} / \mathrm{g}$ to $0.05 \mathrm{~A} / \mathrm{g}$ after 80 charge-discharge cycles, the capacity was almost fully restored, demonstrating that the electrode can tolerate a wide range of current densities. As the current density increased from 0.1 $\mathrm{A} / \mathrm{g}$ to $2 \mathrm{~A} / \mathrm{g}$, the charge-discharge voltage profiles still had similar shapes, but with increasing of the voltage offset (Fig. 3d). This was mainly due to deteriorations through polarization and mechanical energy dissipation aroused by the charge-discharge cycles, which resulted in a stress effect. ${ }^{44}$ The voltage offset decreases the energy efficiency of the cell and can be reduced by further improving the kinetics of the electrode. ${ }^{13}$

It is important but challenging to realize long cycling capability at high rates for current SIBs, owing to the unhelpful side reactions that occur during long cycle life. The FeS ${ }_{2} @ \mathrm{C} / \mathrm{Na}$ batteries maintained a high capacity of $160 \mathrm{mAh} / \mathrm{g}$ after an ultralong lifespan of 10000 cycles at current density of $20 \mathrm{~A} / \mathrm{g}$ (Fig. 3e) and $265 \mathrm{mAh} / \mathrm{g}$ after 2700 cycles at current density of 5 A/g (Fig. S9). The Coulombic efficiency was higher than $99 \%$ during the cycling. To the best of our knowledge, such cycling 
performances are better than those of most reported SIBs (Fig. S10). This outstanding high rate cycling property probably benefits from the unique structure of $\mathrm{FeS}_{2} @ \mathrm{C}$. Firstly, the carbon layer can not only enhance the electrical conductivity, but also accommodate the volume variation of $\mathrm{FeS}_{2}$ during the cycling. Secondly, the small $\mathrm{FeS}_{2}$ particles inside the carbon shell provide shortened $\mathrm{Na}^{+}$and electron transport pathways, which can boost the sodium insertion/extraction. Thirdly, the open structure of the nanoflakes on the surface can enlarge the contact area between the electrode and electrolyte. Most importantly, the unique structure remains almost unchanged after charge-discharge cycling (Fig. S11). 

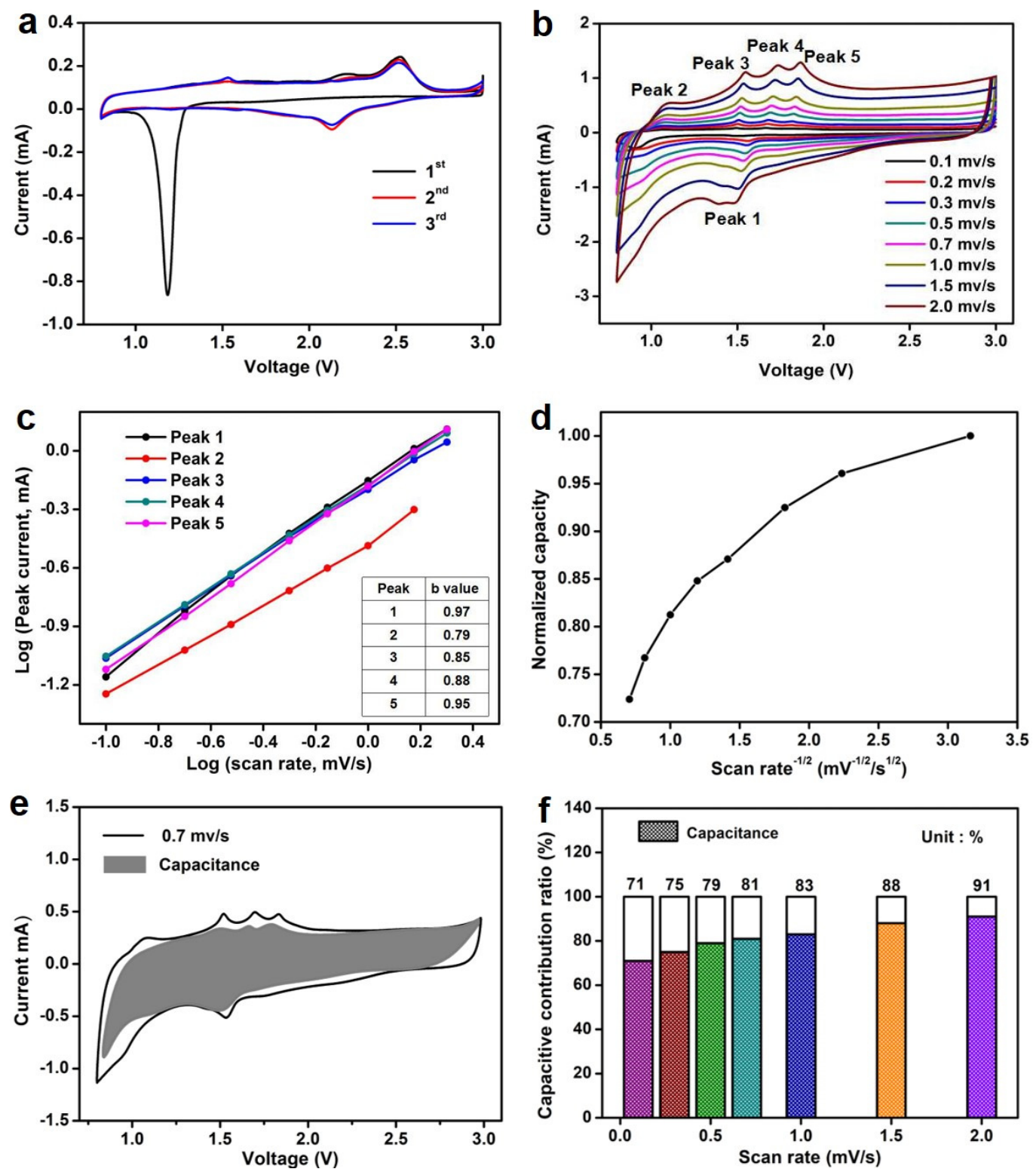

Fig. 4. (a) CVs of the $\mathrm{FeS}_{2} @ \mathrm{C}$ electrode in $\mathrm{SIB}$ at scan rate of $0.1 \mathrm{mV} / \mathrm{s}$ and potential range of $(0.8-3 \mathrm{~V})$. (b) $\mathrm{CVs}$ after 200 cycles of the $\mathrm{FeS}_{2} @ \mathrm{C} / \mathrm{Na}$ cells at various scan rates ranging from 0.1 to $2.0 \mathrm{mV} / \mathrm{s}$. (c) b values of each current peak. (d) Normalized capacity versus (scan rate $)^{1 / 2}$. (e) Capacitance controlled current in $\mathrm{FeS}_{2} @ \mathrm{C}$ at scan rate of $0.7 \mathrm{mV} / \mathrm{s}$. (f) Capacitance contribution ratio at different scan rates.

Kinetic Analysis. To gain insight into the fabulously quick and vast $\mathrm{Na}^{+}$storage properties of the $\mathrm{FeS}_{2} @ \mathrm{C}$ nanorods, the $\mathrm{Na}^{+}$kinetic were analyzed by $\mathrm{CV}$ 
investigations. ${ }^{45,46}$ Fig. 4a displays the initial three $\mathrm{CV}^{4}$ of the $\mathrm{FeS}_{2} @ \mathrm{C} / \mathrm{Na}$ batteries with voltage window of 0.8 to $3 \mathrm{~V}$. The first discharge profile delivers a reduction peak at $1.2 \mathrm{~V}$, corresponding to the phase transition of $\mathrm{FeS}_{2}$, and the subsequent charge profile contains three oxidation peaks located at $1.6,2.2$, and $2.6 \mathrm{~V}$, attributed to multistep $\mathrm{Na}^{+}$deintercalation from the host material. The reduction peak at $1.2 \mathrm{~V}$ moves to $2.2 \mathrm{~V}$ in the following discharge profile due to the gradual phase transformation, while the oxidation peaks maintain their previous position and shape because the conversions are repeatable. ${ }^{12,47}$ Fig.4b shows $\mathrm{CV}$ curves of $\mathrm{FeS}_{2} @ \mathrm{C} / \mathrm{Na}$ after 200 cycles at different scan rate ranging from $0.1-2.0 \mathrm{mV} / \mathrm{s}$, with four oxidation peaks located at $1.1 \mathrm{~V}, 1.51 \mathrm{~V}, 1.69 \mathrm{~V}$ and $1.83 \mathrm{~V}$ (peak 2, peak 3, peak 4 and peak 5), and one reduction peak centered at $1.54 \mathrm{~V}$ (peak1). This is very different from the curves of the initial cycles because of the gradual phase transformation, which is consistent with the charge/discharge profiles shown in Fig. 3a and Fig. S7a.

$\mathrm{CV}$ curves of $\mathrm{FeS}_{2} @ \mathrm{C} / \mathrm{Na}$ after 200 cycles at various scan rates from 0.1 to 10 $\mathrm{mV} / \mathrm{s}$ share a very similar rectangle shape with four oxidation peaks and one reduction peaks (Fig.4b and Fig. S12). It is fascinating to note that the all the small peaks are nearly identical when the scan rate increases from 0.1 to $10 \mathrm{mV} / \mathrm{s}$ (inset of Fig. 4b and Fig. S10), indicating low polarization at high rates. The relationship between the current $i$ corresponding to a fixed voltage and scan rate $v$ can be characterized as:

$$
i=a v^{b}
$$

in which $a$ and $b$ are adjustable parameters. The $b$ value determines whether 
capacitance behavior exist at a certain voltage: $b=0.5$ means that $\mathrm{Na}^{+}$diffusion control the electrochemical reaction, while $b=1$ means that capacitance is dominant. ${ }^{41,48}$ The calculated $b$ values of the five peaks are between 0.79 and 0.97 (Fig.4c), revealing that the capacity originates partly from the capacitance contribution rather than arising completely from diffusion contribution. ${ }^{49,50}$ This pseudocapacitive feature is in agreement with the fact that capacity does not fade significantly as the scan rate ranges from $0.1 \mathrm{mV} / \mathrm{s}$ to $2 \mathrm{mV} / \mathrm{s}$ (Fig. $4 \mathrm{~d}$ ).

The current $i$ at a certain voltage consists of two parts: $k_{1} v$ (the capacitance dominated part) and $k_{2} v^{1 / 2}$ (the diffusion-controlled part).

$$
i=k_{1} v+k_{2} v^{1 / 2}
$$

On the basis of this equation, the relative contributions from surface control (the capacitive part) and diffusion control ( $\mathrm{Na}$ intercalation) at a certain potential can be

determined. ${ }^{50,51}$ As displayed in Fig. 4e, the capacitance contribution to the total capacity at the scan rate of $0.7 \mathrm{mV} / \mathrm{s}$ indicates that the current is capacitance dominated $\left(k_{1} v\right)$. Similarly, the capacitance contribution to the capacity at various scan rate can be quantified and is exhibited in Fig. 4f. The quantified results (Fig. 4f) show that the capacitive contribution increases gradually as the scan rate is speeded up, finally achieving a maximum value of $92 \%$ at $2 \mathrm{mV} / \mathrm{s}$.

\section{- CONCLUSION}

In conclusion, porous $\mathrm{FeS}_{2} @ \mathrm{C}$ nanorods with $\mathrm{FeS}_{2} @ \mathrm{C}$ nanoflakes spreading on the outside surface were synthesized through a simple hydrothermal and annealing process. The as-synthesized $\mathrm{FeS}_{2} @ \mathrm{C}$ nanorods delivered an exceptional rate capacity 
of $265 \mathrm{mAh} / \mathrm{g}$ and $160 \mathrm{mAh} / \mathrm{g}$ in SIBs at $5 \mathrm{~A} / \mathrm{g}$ and $20 \mathrm{~A} / \mathrm{g}$, respectively. Significantly, the $\mathrm{FeS}_{2} @ \mathrm{C} / \mathrm{Na}$ batteries demonstrated spectacular longevity: 2700 cycles at $5 \mathrm{~A} / \mathrm{g}$ and 10000 cycles at $20 \mathrm{~A} / \mathrm{g}$. Kinetic analysis explains the fantastic cycling performance of the $\mathrm{FeS}_{2} @ \mathrm{C}$ electrode through investigating the faradaic pseudocapacitance behavior in $\mathrm{FeS}_{2} @ \mathrm{C} / \mathrm{Na}$ batteries and the great contribution of capacitive charge to capacity. The pseudocapacitance behavior is highly conducive to large current charging and long-term supply of energy. Our work provides a new choice for SIB cathode materials and goes a step further towards realizing fast charging and long-term working energy supplies.

\section{- ASSOCIATED CONTENT}

\section{Supporting Information}

Supporting Information Available: TGA, BET results, TEM, HRTEM images and element mapping of $\mathrm{FeS}_{2} @ \mathrm{C}$ nanorods, XRD pattern of calcined $\mathrm{FeS}_{2} @ \mathrm{C}$ nanorods, SEM images of F-MIL, additional Charge/discharge curves, CV curves and cycle performance of the $\mathrm{FeS}_{2} @ \mathrm{C} / \mathrm{Na}$ battery, SEM images of cycled electrode material, and detailed comparison with relative works

\section{- AUTHOR INFORMATION}

\section{Corresponding authors}

E-mail: *baizhongchao@tyut.edu.cn (Bai Z. C.)

E-mail: *Shi_dou@uow.edu.au (Dou S. X.)

\section{ORCID}


Bai Zhongchao: 0000-0001-6023-9900

\section{Notes}

The authors declare no competing financial interest.

\section{- ACKNOWLEDGMENTS}

This work was supported by National Nature Science Foundations of China (No. 51671140 and 51301117), International Cooperation Project Foundation of Shanxi Province China (No. 201603D421037), Higher School Science and Technology Innovation Project Foundation of Shanxi Province, China (No. 2016128), Research

Project Supported by Shanxi Scholarship Council of China (No. 2015-034), Australian Research Council(ARC) through Discovery Projects (DP160102627), and Linkage Projects(LP160100273).

\section{- REFERENCE}

(1) Kim, H.-S.; Cook, J. B.; Lin, H.; Ko, Jesse S.; Tolbert, Sarah H.; Ozolins, V.;

Dunn, B. Oxygen Vacancies Enhance Pseudocapacitive Charge Storage Properties of $\mathrm{MoO}_{3-x}$. Nat. Mater. 2016, 16, 454-460.

(2) Bruce, P. G.; Scrosati, B.; Tarascon, J. M. Nanomaterials for Rechargeable Lithium Batteries. Angew. Chem. Int. Ed. 2008, 47, 2930-2946.

(3) Dunn, B.; Tarascon, J. M. Electrical Energy Storage for the Grid: A Battery of Choices. Science 2011, 334, 928-935.

(4) Goodenough, J. B. Electrochemical Energy Storage in a Sustainable Modern 
Society. Energy Environ. Sci. 2014, 7, 14-18.

(5) Ellis, B. L.; Lee, K. T.; Nazar, L. F. Positive Electrode Materials for Li-Ion and Li-Batteries. Chem. Mater. 2010, 22, 691-714.

(6) Choi, N. S.; Chen, Z.; Freunberger, S. A.; Ji, X.; Sun, Y. K.; Amine, K.; Yushin, G.;

Nazar, L. F.; Cho, J.; Bruce, P. G. Challenges Facing Lithium Batteries and Electrical Double-Layer Capacitors. Angew. Chem. Int. Ed. 2012, 51, 9994-10024.

(7) Slater, M. D.; Kim, D.; Lee, E.; Johnson, C. S. Sodium-Ion Batteries. Adv. Funct. Mater. 2013, 23, 947-958.

(8) Xiao, Y.; Lee, S. H.; Sun, Y.-K. The Application of Metal Sulfides in Sodium Ion Batteries. Adv. Energy Mater. 2017, 7, 299-308.

(9) Zhang, K.; Park, M.; Zhou, L. M.; Lee, G.-H.; Shin, J.; Hu, Z.; Chou, S.-L.; Chen, J.; Kang, Y.-M. Cobalt-Doped $\mathrm{FeS}_{2}$ Nanospheres with Complete Solid Solubility as a High-Performance Anode Material for Sodium-Ion Batteries. Angew. Chem. Int. Ed. 2016, 55, 12822-12826.

(10) Zhang, Y. H.; Wang, N. N.; Sun, C. H.; Lu, Z. X.; Xue, P.; Tang, B.; Bai, Z. C.; Dou, S. X. 3D Spongy $\mathrm{CoS}_{2}$ Nanoparticles/Carbon Composite as High-Performance Anode Material for Lithium/Sodium Ion Batteries. Chem. Eng. J. 2018, 332, 370-376.

(11) Zhang, Y. H.; Wang, N. N.; Xue, P.; Liu, Y. L.; Tang, B.; Bai, Z. C.; Dou, S. X. $\mathrm{Co}_{9} \mathrm{~S}_{8} @$ Carbon Nanospheres as High-performance Anodes for Sodium Ion Battery. Chem. Eng. J. 2018, 343, 512-519.

(12) Douglas, A.; Carter, R.; Oakes, L.; Share, K.; Cohn, A. P.; Pint, C. L. Ultrafine Iron Pyrite $\left(\mathrm{FeS}_{2}\right)$ Nanocrystals Improve Sodium-Sulfur and Lithium-Sulfur 
Conversion Reactions for Efficient Batteries. ACS Nano 2015, 9, 11156-11165.

(13) Zhu, Y. J.; Han, X. G.; Xu, Y. H.; Liu, Y. H.;Zheng, S. Y.; Xu, K.; Hu, L. B.;

Wang, C. S. Electrospun Sb/C Fibers for a Stable and Fast Sodium-Ion Battery Anode. ACS Nano 2013, 7, 6378-6386.

(14) Zhu, Y. J.; Suo, L. M.; Gao, T.; Fan, X. L.; Han, F. D.; Wang, C. S. Ether-based Electrolyte Enabled $\mathrm{Na} / \mathrm{FeS}_{2}$ Rechargeable Batteries. Electrochem. Commun. 2015, 54, $18-22$.

(15) Guan, C.; Liu, J. L.; Wang, Y. D.; Mao, L.; Fan, Z. X.; Shen, Z. X.; Zhang, H.; Wang, J. Iron Oxide-Decorated Carbon for Supercapacitor Anodes with Ultrahigh Energy Density and Outstanding Cycling Stability. ACS Nano 2015, 9, 5198-5207.

(16) Li, L. S.; Meng, F.; Jin, S. High-capacity Lithium-Ion Battery Conversion Cathodes Based on Iron Fluoride Nanowires and Insights into the Conversion Mechanism. Nano Lett. 2012, 12, 6030-6037.

(17) Wu, R. B.; Qian, X. K.; Rui, X. H.; Liu, H.; Yadian, B.; Zhou, K.; Wei, J.; Yan, Q. Y.; Feng, X. Q.; Long, Y.; Wang, L. Y.; Huang, Y. Z. Zeolitic Imidazolate Framework 67-Derived High Symmetric Porous $\mathrm{Co}_{3} \mathrm{O}_{4}$ Hollow Dodecahedra with Highly Enhanced Lithium Storage Capability. Small 2014, 10, 1932-1938.

(18) Wu, R. B.; Qian, X. K.; Zhou, K.; Wei, J.; Lou, J.; Ajayan, P. M. Porous Spinel $\mathrm{Zn}_{x} \mathrm{Co}_{3-x} \mathrm{O}_{4}$ Hollow Polyhedra Templated for High-Rate Lithium-Ion Batteries. ACS Nano 2014, 8, 6297-6303.

(19) Huang, G.; Zhang, F. F.; Du, X. C.; Wang, J. W.; Yin, D. M.; Wang, L. M. Core-Shell $\mathrm{NiFe}_{2} \mathrm{O}_{4} @ \mathrm{TiO}_{2}$ Nanorods: An Anode Material with Enhanced 
Electrochemical Performance for Lithium-Ion Batteries. Chem. -Eur. J. 2014, 20, 11214-11219.

(20) Huang, G.; Zhang, L. L.; Zhang, F. F.; Wang, L. M. Metal-Organic Framework Derived $\mathrm{Fe}_{2} \mathrm{O}_{3} @ \mathrm{NiCO}_{2} \mathrm{O}_{4}$ Porous Nanocages as Anode Materials for Li-Ion Batteries. Nanoscale 2014, 6, 5509-5515.

(21) Cao, X. H.; Zheng, B.; Rui, X. H.; Shi, W. H.; Yan, Q. Y.; Zhang, H. Metal Oxide-Coated Three-Dimensional Graphene Prepared by the Use of Metal-Organic Frameworks as Precursors. Angew. Chem. Int. Ed. 2014, 126, 1428-1433.

(22) Cheng, F. Y.; Tao, Z. L.; Liang, J.; Chen, J. Template-Directed Materials for Rechargeable Lithium-Ion Batteries. Cheminform 2012, 39, 667-681.

(23) Dylla, A. G.; Henkelman, G.; Stevenson, K. J. Lithium Insertion in Nanostructured $\mathrm{TiO}_{2}$ (B) Architectures. Acc. Chem. Res. 2013, 46, 1104-1112.

(24) Liu, B.; Shioyama, H.; Akita, T.; Xu, Q. Metal-Organic Framework (MOF) as Template for Porous Carbon Synthesis. J. Am. Chem. Soc. 2008, 130, 5390-5391.

(25) Liu, B.; Zhang, X. B.; Shioyama, H.; Mukaia, T.; Sakaia, T.; Xu, Q. Converting Cobalt Oxide Subunits in Cobalt Metal-Organic Framework into Agglomerated $\mathrm{Co}_{3} \mathrm{O}_{4}$ Nanoparticles as an Electrode Material for Lithium Ion Battery. J. Power Sources 2010, 195, 857-861.

(26) Pachfule, P.; Shinde, D.; Majumder, M.; Xu, Q. Fabrication of Carbon Nanorods and Graphene Nanoribbons from a Metal-Organic Framework. Nature Chem. 2016, 8, 718-724.

(27) Luo, W.; Chen, X. Q.; Xia, Y.; Chen, M.; Wang, L. J.; Wang, Q. Q.; Li, W.; Yang, 
J. P. Surface and Interface Engineering of Silicon-Based Anode Materials for Lithium-Ion Batteries. Adv. Energy Mater. 2017, 1701083, 1-28.

(28) Yu, L. T.; Liu, J.; Xu, X. J.; Zhang, L. G.; Hu, R. Z.; Liu, J. W.; Ouyang, L. Z.; Yang, L. C.; Zhu, M. Ilmenite Nanotubes for High Stability and High Rate Sodium-Ion Battery Anodes. ACS Nano 2017, 11, 5120-5129.

(29) Sun J.-K.; Xu Q. Functional Materials Derived from Open Framework Templates/Precursors: Synthesis and Applications. Energy Environ. Sci. 2014, 7, 2071-2100.

(30) Wang H. L.; Zhu Q.-L.; Zou, P. Q.; Xu Q. Metal-Organic Frameworks for Energy Applications. Chem 2017, 2, 52-80.

(31) Dang, S.; Zhu, Q.-L.; Xu, Q. Nanomaterials Derived from Metal-Organic Frameworks. Nat. Rev. Mater. 2017, 3, 17075.

(32) Bai, Z. C. Zhang, X. Y.; Zhang, Y. W.; Guo, C. L.; Tang, B. Facile Synthesis of Mesoporous $\mathrm{Mn}_{3} \mathrm{O}_{4}$ Nanorods as a Promising Anode Material for High Performance Lithium-Ion Batteries. J. Mater. Chem. A 2014, 2, 16755-16760.

(33) Lu, Z. X.; Wang, N. N.; Zhang, Y. H.; Xue, P.; Guo, M. Q.; Tang, B.; Bai, Z.; Dou, S. X. Pyrite FeS $\mathrm{F}_{2} @ \mathrm{C}$ Nanorods as Smart Cathode for Sodium Ion Battery with Ultra-Long Lifespan and Notable Rate Performance from Tunable Pseudocapacitance. Electrochim. Acta 2018, 260, 755-761.

(34) Xue, P.; Wang, N. N.; Wang, Y. X.; Zhang, Y. H.; Liu, Y. L.; Tang, B.; Bai, Z.; Dou, S. X. Nanoconfined SnS in 3D Interconnected Macroporous Carbon as Durable Anodes for Lithium/Sodium Ion Batteries. Carbon 2018, 134, 222-231. 
(35) Cho, J. S.; Lee, J.-K., Kang, Y. C. Graphitic Carbon-Coated FeSe 2 Hollow Nanosphere-Decorated Reduced Graphene Oxide Hybrid Nanofibers as an Efficient Anode Material for Sodium Ion Batteries. Sci. Rep. 2016, 23699, 1-13.

(36) Bai, Z. C.; Zhang, Y. W.; Zhang, Y. H.; Guo, C. L.; Tang, B. Hierarchical $\mathrm{MoS}_{2} @$ Carbon Microspheres as Advanced Anodes for Li-Ion Batteries. Chem. - Eur. J. 2015, 21, 18187-18191.

(37) Sourisseau, C.; Cavagnatr, R.; Fouassier, M. The Vibrational Properties and Valence Force Fields of $\mathrm{FeS}_{2}, \mathrm{RuS}_{2}$, Pyrites and $\mathrm{FeS}_{2}$ Marcasite. J. Phys. Chem. Solids 1990, 52, 537-544.

(38) Zhu, Y. J.; Fan, X. L.; G.; Suo, L. M.; Luo, C.; Gao, T.; Wang, C. S. Electrospun $\mathrm{FeS}_{2} @$ Carbon Fiber Electrode as a High Energy Density Cathode for Rechargeable Lithium Batteries. ACS Nano 2016, 10, 1529-1538.

(39) Xu, J.; Xue, H. T.; Yang, X.; Wei, H. X.; Li, W. Y.; Li, Z. P.; Zhang, W. J.; Lee, C.- S. Synthesis of Honeycomb-Like Mesoporous Pyrite $\mathrm{Fes}_{2}$ Microspheres as Efficient Counter Electrode in Quantum Dots Sensitized Solar Cells. Small 2014, 10, 4754-4759.

(40) Li, J. B.; Yan, D.; Zhang, X. J.; Hou, S. J.; Li, D. S.; Lu, T.; Yao, Y. F.; Pan, L. K. In Situ Growth of $\mathrm{Sb}_{2} \mathrm{~S}_{3}$ on Multiwalled Carbon Nanotubes as High-Performance Anode Materials for Sodium-Ion Batteries. Electrochim. Acta 2017, 228, 436-446.

(41) Hu, Z.; Zhu, Z. P.; Cheng, F. Y.; Zhang, K.; Wang, J. B.; Chen, C. C.; Chen, J. Pyrite $\mathrm{FeS}_{2}$ for High-Rate and Long-Life Rechargeable Sodium Batteries. Energy Environ. Sci. 2015, 8, 1309-1316.

(42) Zhang, S. S., The Redox Mechanism of $\mathrm{FeS}_{2}$ in Non-Aqueous Electrolytes for 
Lithium and Sodium Batteries. J. Mater. Chem. A 2015, 3, 7689-7694.

(43) Shadike, Z.; Zhou, Y.-N.; Ding, F.; Sang, L.; Nam, K.-W.; Yang, X.-Q.; Fu, Z.-W.

The New Electrochemical Reaction Mechanism of $\mathrm{Na} / \mathrm{FeS}_{2}$ Cell at Ambient Temperature. J. Power Sources 2014, 260, 72-76.

(44) Bai, Z. C.; Zhang, Y. H.; Zhang, Y. W.; Guo, C. L.; Tang, B.; Sun, D. MOFs-Derived Porous $\mathrm{Mn}_{2} \mathrm{O}_{3}$ as High-Performance Anode Material for Li-Ion Battery. J. Mater. Chem. A 2015, 3, 5266-5269.

(45) Brezesinski, T.; Wang, J.; Tolbert, S. H.; Dunn, B. Ordered Mesoporous Alpha- $\mathrm{MoO}_{3}$ with Iso-Oriented Nanocrystalline Walls for Thin-Film Pseudocapacitors. Nat. Mater. 2010, 9, 146-151.

(46) Muller, G. A.; Cook, J. B.; Kim, H.-S.; Tolbert, S. H.; Dunn, B. High Performance Pseudocapacitor Based on 2D Layered Metal Chalcogenide Nanocrystals. Nano Lett. 2015, 15, 1911-1917.

(47) Walter, M.; Zünd, T.; Kovalenko, M. V. Pyrite $\left(\mathrm{FeS}_{2}\right)$ Nanocrystals as Inexpensive High-Performance Lithium-Ion Cathode and Sodium-Ion Anode Materials. Nanoscale 2015, 7, 9158-9163.

(48) Wang, J.; Polleux, J.; James Lim, A.; Dunn, B. Pseudocapacitive Contributions to Electrochemical Energy Storage in $\mathrm{TiO}_{2}$ (Anatase) Nanoparticles. J. Phys. Chem. C 2007, 111, 14925-14931.

(49) Chen, C. J.; Wen, Y. W.; Hu, X. L.; Ji, X. L.; Yan, M. Y.; Mai, L. Q.; Hu, P.; Shan, B.; Huang, Y. H. $\mathrm{Na}^{+}$Intercalation Pseudocapacitance in Graphene-Coupled Titanium Oxide Enabling Ultra-Fast Sodium Storage and Long-Term Cycling. Nat. Commun. 
2015, 6, 6929-6935.

(50) Chao, D. L.; Zhu, C. R.; Yang, P. H.; Xia, X. H.; Liu, J. L.; Wang, J.; Fan, X. F.;

Savilov, S. V.; Lin, J. Y.; Fan, H. J.; Shen, Z. X., Array of Nanosheets Render Ultrafast and High-Capacity Na-Ion Storage by Tunable Pseudocapacitance. Nat. Commun. 2016, 7, 12122-12130.

(51) Augustyn, V.; Come, J.; Lowe, M. A.; Kim, J. W.; Taberna, P-L.; Tolbert, S. H.; Abruna, H. D.; Simon, P.; Dunn, B., High-Rate Electrochemical Energy Storage Through $\mathrm{Li}^{+}$Intercalation Pseudocapacitance. Nat. Mater. 2013, 12, 518-522. 


\section{Table of Contents}

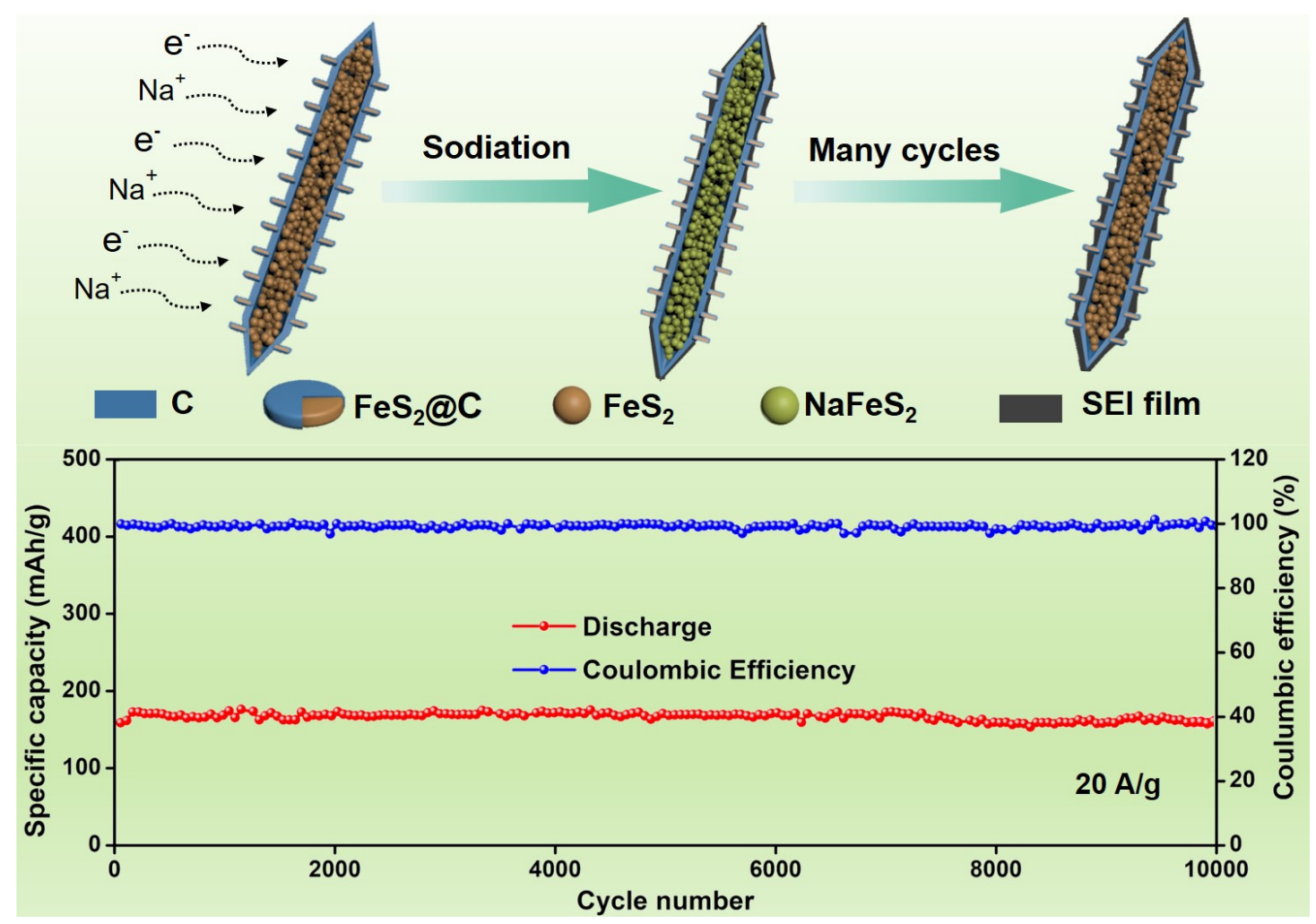

